\title{
Reader-response Approach Used in Chinese EFL Context: An Alternative Approach to Teach Literature Jiang Qian
}

\author{
School of Foreign Languages, Yunnan Normal University, Kunming, Yunnan, P. R. China \\ 1271530736@qq.com
}

Keywords: reader-response theory, reader-response approach, EFL context, literature.

\begin{abstract}
Literature is used as an authentic material to teach English reading and accelerate the language acquisition in Chinese EFL context. This paper provides an detailed analysis on the reader-response approach which is based on reader-response theory to demonstrate that by putting the relation between reader and literary text, reader-response approach challenges the traditional Chinese way of teaching literature. Through emphasizing the reader's interpretation of the text, students can go beyond the barrier of language difficulties and achieve right levels of language competence by adopting reader-response approach in literature teaching in Chinese EFL context.
\end{abstract}

\section{Introduction}

Reader-response approach which is based on the reader-response theory, places emphasis on the synthesis between reader and text used in EFL literature teaching context. It can not only help students develop the competence for literature appreciation, but also can create opportunities for students to use the target language to express their own feelings. Reader-response approach challenges the traditional Chinese way of teaching literature. It also provides a new way of thinking for the Chinese literature teacher. By adopting both reader-response approach and some aspects of Chinese traditional teaching approach to teach literature in Chinese EFL context, while encouraging students' genuine responses during the process of literature teaching, students can go beyond the barrier of language difficulties and move towards the critical appreciation of the literary text.

\section{Pedagogical challenge}

Literature is a compulsory course for English major students in the universities and colleges in China and the course is separated from other language courses which focus on improving the students' language proficiency in writing, reading, listening and speaking skills.

The traditional literature teaching in China has been based on a form of "monologue teaching", which has been focusing on a teacher-centered or text-centered form in a lecture mode [1]. During the teaching process, after introducing the author and the historical background of the story, the teacher usually explains the difficult vocabularies and lexical sets to the students, which are vital to EFL students. Then the students read the text. One of the most criticized aspects of Chinese traditional literature teaching is that the text book or the teacher provides a definite explanation to the main idea, the author's purpose or the subtle meaning of the text. Students often do not need to do any self-thinking or reflection of the literary text. They only have to consult the dictionary to find the meaning of the new vocabularies and remember the author's backgrounds and the 'main idea' of each literary text, which are given by the textbook, for the future examination. Students can never learn to read and think critically and independently about the literary text. Literature becomes a kind of imposed information to be memorized by them. The literature course only means a passing grade for them, and they usually forget what they have learned soon after the examination.

The pedagogical challenge in the traditional teaching of literature in China lies in its negligence of the interaction between the text and reader and its indifference to the reader's role. Lu Jun declares that "the reader plays a decisive role in literary activities in the sense that putting the author, the text and the reader together, which can be a complete literary activity. The text cannot exist until it is read 
by its readers." [2] Therefore, an alternative approach based on the reader response theory to teach literature can fulfil both the language and literature purpose in literature teaching and learning.

\section{Literature review}

\subsection{Review of literature on Reader-Response Theory}

According to Margaret Drabble, reader-response theory is a body of literary investigations into the nature of the reader's activity in the process of understanding literary texts, which is posing a growing influences on literature teaching in recent years [3].

From 1980s, reading comprehension is viewed as an alternative process between the text and the reader's prior knowledge. The reader constructs and interprets the meaning of the text based on his or her own experiences or background knowledge during their reading process. Based on the theory, the reader-response theory places emphasis on the reader's creative role in the reading process, which declares that the act of reading is like a dialogue between the reader and the text. The reader actively constructs meaning of the text by responding to the text and reflecting on their responses [4]. According to the theory, reading is viewed as a transactional act between the reader and the text. The reader comes to the text with all his or her experiences, beliefs and assumptions and continuously interprets the text according to them. Text does not have the authority over reader. The reader integrates his or her own experiences, explanations with the text, and creates the meaning of the text during the reading process[5].

In reader-response theory, Rosenblatt points out that there are two ways of mutual conditioning transactions between readers and text, that is reading can be efferent (non-aesthetic), and aesthetic, and the same text can be read either efferently or aesthetically and the reading can fall on a continuum ranging from efferent to aesthetic [4]. Carlisle further explains efferent reading as the reader's attention is focused on the information he or she can recall to use after reading, and aesthetic reading as when the reader's attention is focused on the experience of the reading itself. "During the reading process, the reader is attending both to the meaning of the words on the page and to feelings, ideas, images and characters being evoked with the help of the text "[6]. Most of the reading activity is a mixture of both efferent and aesthetic.

\subsection{Reader-response theory used in EFL context}

Since English is taught in China as a foreign language, as a very motivating and authentic material, literature is found very helpful in student's language and their understanding to another culture Through literature learning, students can get easier access to the culture background and the language acquisition will be encouraged. Students read to benefit from literature works to get a general idea of the development of the target language and to enhance their language awareness and linguistic competence by learning the characteristics and variations of English language in different periods.

Reader-response approaches based on reader-response theory challenge the traditional text-authorized concept. The former emphasizes on the interpretation of the the text and the reader's creative role in the reading process and is an effective way of involving the students with the literary text they are reading in EFL contexts. Unlike the traditional teaching or the text oriented way of teaching, reader-response approach used in language classroom is reader-centered with more engagement between reader and text. A classroom that uses reader-response theory is a much more complex learning environment than text-centered reading. The active and communicative nature of reader-response approach suggests that it would complement the modern trends in EFL [6].

Reader-response approach can encourage students' response and stress learner's production of the target language. It focuses on the reader's story of reading. Each response of the reader can be a stepping stone towards a further response and views the reader as a meaning maker of the text, and the reading process as a process of reader telling his or her own story of reading. Reader-response approach is reader-based and "because of its continuous interest in learner's story of reading, the reader-response approach will assign fewer task, and attempt to draw more from each of them"[5]. For example, by asking students questions like "How did you feel while you are reading?" rather than "What does the author intend?" 
Ali develops the framework of methodology in reader-response approach in EFL context including invoking schema by creating pre-reading activities;sharing initial responses to broaden students perspectives; teaching and helping students to refine their response by intervening in the transaction between reader and text; and using enlightening projects like posters and interviews to provide readers with more appreciation of the text during his or her reading process. " the basic assumption underlying this framework is that teaching should allow for the natural sequence of response to take place, the students should be taken on the whole creative ride of the response journey ranging from personal involvement to reading awareness" [7]

Reader-response approach has an increasing importance in EFL literature teaching context. It can evoke both the reader's aesthetic experience and literary experience during reading, thus, reading of literature in an EFL context can provide students with enjoyment in reading and an appreciation of literature.

\section{Discussion}

Reader-response approach provides a great challenge to Chinese traditional literature teaching. It offers both the Chinese literature teacher and the students a new way of thinking. The reader's role should be re-considered in view of reader-response theory. Reader-response approach will impose a good effect on Chinese literature teaching and bring a rethinking of the reader's role. Reader-response approach emphasizes the reader's creation of the text meaning and the text is the reader's text not the author's text by encouraging the reader's response during the reading process. As a result, the reader can get involved in the text, and use his or her experiences to interpret the literary text. Much reflections of the reader can be evoked during the reading process, thus reading literature is not only to get information, but also to appreciate the literary work.

However, it is necessary for Chinese students to know that there is not a definite 'right' response to any single literary text. It is the reader that creates the meaning of the the text upon his or her own experiences. Reader should be regarded as the meaning-maker as well. Literature should be learned with more flexibility and reflections. This will also arouse the students' interests in the literature and make them do more thinking. Literature is not something far way from their life, but close to their own experiences. Through learning literature by reflecting on their own responses, they can learn to read critically and think critically and get the most out of their study while developing their own competence in appreciation of the literature.

English language is a major foreign language taught in China. Students have fairly limited access to spoken and written English. These two language skills often play a primary important role for stimulating language acquisition. Literature may provide a particular appropriate way of accelerating this acquisition, as "it provides meaningful and memorable context for processing and interpreting new language"[8]. Reader-response approach encourages students responses in the literary text through activities like group discussion, sharing initial responses, or re-writing, so that students can get a good opportunity to use and produce target language.

However, in Chinese EFL context, two important things must be considered when adopting reader-response approach. First is the language difficulties. Because reading aesthetically presupposes the ability to read with some fluency, and the experiential background to handle the level of an author's language and ideas, all of the reader's experience with written language, reading, ideas, and the world contribute to his or her ability to read aesthetically and efferently. Language difficulties must bet taken into account because the access to the target language is restricted if students can not have a basic level of comprehension [9]. Only when students get some level of language competence can they really read efferently and aesthetically in the reading process. For Chinese students, the language difficulties mainly lie in the vocabularies and some lexical structure. Therefore, it is necessary for the teacher to so some pre-reading works on vocabulary and sentence structures. This aspect of the traditional way of teaching can not be thrown away.

The second thing to be considered is the culture barrier. Many literary text in some way reflect their own cultures, such as the totality of society during a specific historical period. Literature also are written by authors lived in many different countries and widely divergent cultures in different 
historical periods. "By exposing students to literature in English, teacher should be asking them to think about the range of cultures from which literature in English is produced" [8]. So, as a rule, it is better to choose literature text which are not too far beyond the students' normal reading comprehension and their background experiences for teaching. The text should suit the students' interests, culture values, and ability level in order to evoke and construct the schema for the students, which will increases the chances of the text being enjoyed.

\section{Conclusion}

Experience has show that reader-response approach is very effective in helping students to achieve competence in reading and appreciation of literature in Chinese EFL context. However, it is not appropriate to totally throw away the Chinese traditional approach to teach literature. Literature teaching must be culturally and institutionally appropriate. The combination of reader-response approach and traditional approach can provide the students with the language competence and confidence essential to engagement in literature course. Students' acquisition of target language also can be accelerated by teacher's encouraging their response during the literature reading. Moreover, it is also important to caution against superficial personal response. The role of the teacher here is vital. Teacher should avoid imposing and preconceived notions about the proper way to react to any work. What we do not need is an approach which encourages lazy surface thinking. Reader-response approach applied by well-informed teachers should avoid this danger. Clearly, further research is needed into the potential of reader-response approach in the Chinese EFL classroom. The limited study described in this paper points to such potential.

\section{References}

[1] Lv Hongling, Dialogues and Reflections, a study of foreign literature on the threshold of new century, Hehai University Press, pp. 61, 2006.

[2] Lv Jun, Value Philosophy and Translation Criticism, Foreign Languages, (1) pp.75, 2006.

[3] Margaret Drabble, The Oxford Companio to Engish Literature, Beijing: Foreign Language Teaching and Research Press, pp. 841, 2005.

[4] Rosenblatt, L., Continuing the Coversation: a clarification, Research in the Teaching of English, 29 Oct., 1995.

[5] Hirvela, A., Reader-response Theory and ELT. ELT Journal, vol. 50/2, pp.127-134, 1996.

[6] Carlisle, A., Reading logs: an application of reader-response theory in ELT, ELT Journal, vo; 54/1, pp. 12-19, 2000.

[7] Ali, S., The reader response approach: an alternative for teaching literature in a second language. Journal of Reading, vol 37:4, pp. 288-295,1994.

[8] Lazar, G., Literature and Language Teaching. Cambridge: Cambridge University Press, pp. 17, pp.16, 1993.

[9] Carter, R., \& Long, M., Teaching Literature. Longman Handbooks for Language Teachers, 1991. 